\title{
A Comparative Study of Sex Education for Teenagers in America and China \\ An-Ran CHEN
}

Chengdu Sport University, Chengdu, Sichuan, China

664289432@qq.com

Keywords: Sex Education; China; America; status; suggestions

\begin{abstract}
At present, in many countries, sex education is no longer a resistance, criticism and sensitive issue of perversion, developed countries, such as the United States, Britain, Canada, provide appropriate sex education to teenagers, and has carried out many sex education and reproductive health services. China has made some progress of teenage sex education, but also has some problems. This thesis compares the sex education between United States and China in the aspect of family, school and society, and learns some experience from America.
\end{abstract}

\section{Introduction}

As is known to all, the Confucius' theory has occupied a thousand years of the Chinese mental world, even today. This theory strongly emphasizes "good manners", which implies that ideas and behaviors related to sex should be considered as obscenity and evil. Although today's Chinese people are much more open, sex still remains a sensitive topic in our daily life [1].

Traditionally in China, speaking about sex was a private matter only between close friends rather than in public. Unfortunately, this conservative attitude led to inadequate sexual education for children. While stemming from curiosity, many youngsters have tried to get information from adult websites and pornographic videos or books. As a result, pregnancies, premarital sex and sexually transmitted diseases have risen among teenagers in recent years. Girls who have abortions are much younger. Most of them are junior middle school students aged 14. The youngest patient gone through with the abortion was only 13 . Unpredictably some girls even had abortions many times [2].

It's miserable for anyone involved - parents are afraid \& children are mortified — which is probably why the talk so often comes after the fact. In the latest study on parent-child talks about sex and sexuality, researchers found that more than $40 \%$ of adolescents had had intercourse before talking to their parents about safe sex, birth control or sexually transmitted diseases.

Fortunately with the increasing of teenagers' sex education, every country pays more attention to research this problem. Among them, America is one of the earliest countries to implement sex education. With the quickening progress of the world and the mixed media anomie, China has inevitably influenced by the western countries' idea of "sexual freedom". This leaded to the contemporary of young humanity idea being more open, and misled the attitude to sex of young students.

Thus this paper introduces some similarity and difference between China and America about teenage sex education. China should get some suggestion from America.

\section{Concept and Importance of Sex Education}

Adolescence refers to the gradual development of children to adult transition. During this period students have lots of changes in body frames, such as sexual organs and function. On one hand, it stimulates mature awareness of the middle school students; on the other hand, it brings many heterosexual contacts and psychological health problems to students. Therefore, it is necessary to give students the sex education. 


\section{Concept of Sex Education}

What is the meaning of sexuality? Sexuality refers to the expression of any sexually suggestive and intimate human relationships, covering physiological sex under the influence of sexual orientation. It covers the physical, psychological, sociological (i.e. the political policy and mental areas within the scope of the religious perceptual behavior). Therefore, sex education refers to the knowledge. Sex education is throughout a human concept development, attitude, belief and value to a confirmation process. Sex education has the content of the biological, social culture, psychology and spiritual latitude.

\section{Importance of Sex Education}

Sex education is particularly important for teenagers. The rapid occurrence of physiological changes would have a psychological fluctuations and curiosity for new things, so the lack of sex education will bring young people's mental confusion. United Nations Population Fund released that at present every 14 seconds a youth infected with the HIV. This is mainly because that these people who cannot obtain information on the prevention of disease caused by the lack of information and skills.

\section{Status of Adolescent Sex Education in China}

\section{Current Status of Sex Education in China}

The sex education of young people in China had began rapidly development from August 24, 1988. The former State Education Commission and the State Family Planning Commission jointly issued the notice of education in adolescence in high school[3]. The release of the notice marked the formal sex education incorporated into the content of our high school education. Previously, sex education in China has been in a state of confinement and sprout. The reform and open policy brought the penetration of western culture, but also caused the people to think about the traditional culture, especially at its pinnacle----the Cultural Revolution. This collision of old vs new concepts and Eastern vs Western cultures makes it swing to traditional morality, and hedonism and asceticism of feudal freedom of Western sexual[4].

In recent years, due to the influences of western ideas of sexual freedom, abortion and youthprostitution have become a serious social problem. There are many reasons for this phenomenon, including their youth, parents, schools, society and the contradiction between education and action in various groups. So the education of the youth development was filled with chaos and confusion. The lack of clear guidelines and science makes them incomprehensible to put forward.

\section{Achievement and Insufficiency of Chinese Teenage Sex Education}

In the information age, the development of economy and the explosion of knowledge make the worldwide communication possible. After $80 \mathrm{~s}$, a variety of sex-related literary works, television, movies, newspapers and magazines have appeared. All kinds of porn Website pervasive invasion of young people. The social environment in the debauchery is a charming figure of its desire to entice young people to break freedom[5].

Nowadays, schools set related courses in a very awkward position. On one hand, the education department has to pay attention to the variety of social problems and pressures of sex education; on the other hand, there still exist the pressure of examinations. Adolescence education carries out the idea that the performance of moral leadership and Dean head teacher organizations, expert lectures, or simply in biology class with one or two hours, "Dragonfly point of water" like to talk about the physical health knowledge.

Family education has a vital role, especially in sex education. Now, there are many parents are still under the influence of the traditional culture who are still not caring about the sexual education.

As a sex education subject of teenagers, the physiological maturity decides they are eager to know sex knowledge. The inner conflict between their physiological and the psychological 
development is imbalanced. Therefore, they have to meet other possible ways in society, such as newspapers, virtual network, etc. This will surely make them easy to produce sexual moral deviation under the influence of the negative factors and the wrong way.

\section{Status of Sex Education of the United States}

\section{Current Status of American Youth Sex Education}

In the U.S, adolescent sexuality is a serious social problem. Centers for Disease Control reported that before the age of $20,75 \%$ of women and $86 \%$ of men have experienced sexual intercourse. About $1 / 4$ of 15 years old female and $1 / 3$ of the 15 years old male have had sexual intercourse experience[6]. In some sex education experts' view that America's sexual education is successful.

\section{Achievement and Insufficiency of American Teenage Sex Education}

With the development of sex education in America, the rate of STD, HIV has been declining, especially the proportion of teenage pregnancy.

Teenagers' sexual health is facing a crisis with the sexual maturity of their own and transmission of social information. An obvious reason caused by the sexual health is moral decay. It is generally the lack of self of the virtues. The achievement of sex education will be devoid of moral nihilism and advocate the excellent character of respect, responsibility and reserve, loyalty of entire society.

Sex education is based on moral education on the basis of comprehensive education. The openness of modern society makes the family, school and community connected with each other more and more closely. Therefore, the moral education of students in the school can not simply rely on the support of all areas of society but need to communicate with each other. Thus, the good social values and formation of morality can make education productive in sex education.

In recent years, there are two views about schools of sex education to be held in American. Both are in favor of adolescent sex education in schools, but there are differences in the specific objectives. The United States to a sexual information and education committee of SIECUS puts forward the safe of sex comprehensive education target and emphasis on individual rights that sex should never be forced or denied. In order to induce the damage, they argued that schools should be mainly made adolescent sex education to teach students to use condoms during their sex. Another school of sexual health institute for medical research in the United States MISH puts forward the target of moral education and promotes the sex education of character-based of abstinence approach that is adolescent sex education curriculum should be promoted students to maintain virginity until they ready to marry. They believe that sex is not just from the values determined by the scientific knowledge but also taught young people to use the core ethical morality[7].

According to the survey of Kaiser Family Foundation national, there was 93 percent of American parents support comprehensive sex education for children, including contraception education. Many parents believe that letting children understand the information of reproduction, contraception, sexually transmitted diseases and AIDS can reduce youth unplanned pregnancy and prevent these infected venereal disease. Thus young people can make a right decision in sexual behavior[8].

Although many American parents approve of sex education should start from the family, the adolescent sexual health education experts insist that the young American families provide little content and time about sex education. According to a study, only $10 \%$ of U.S. families have a habit to can maintain to talk about this issue regularly. And the vast majority of young people and their parents are not satisfied with the quantity and quality of issue that they discuss. According to another survey, $81 \%$ of parents think they get sex answer from their children is true, but only $22 \%$ of the children think all the same[9].

Students' psychological development and sexual knowledge is imbalanced. Young people often have serious doubts roles, but only a handful of people consciousness himself in the wrong gender role. In recent years, teenagers' illegal sex becomes the most worried social issues. The most typical point is the performance teenagers' provocative behavior and bad language, such as speaking 
abusive language and wearing too revealing clothes, etc. Teenage sex offence is a violation is a violation of laws and moral. The obscene telephone, bare and vaginal ringworm are the typical performance.

\section{Suggestions to Sex Education in China}

\section{Establish a Liberal Sexual Concept}

Emancipating the mind and seeking truth from facts are the basic principle of all the work. Establishing liberal sexual concept has become a top priority among young people nowadays. Liberal sexual concept should have such meaning. Liberal sexual attitude requires sexual behavior is clean, enjoy and mutual. Clean means one's body and psychological both are clean[10].

Setting up the concept of liberal sexual is the most important priority of sex education, especially enhance the value guidance of sex education of young people. Value is the core in all concepts. It determines people's expectations, attitudes and behavior of the psychological foundation. Values are reflection of existence the society. It is a principle that people used to evaluate the behavior and things. The school education plays a very important role in formation of teenage sex value, which is embodied in embodied in the process of the value guidance of concept of adolescent sex. However, the guide does not mean to drive, to fool or deceive.

Teenage sex education is a kind of value guidance, referring to sex education is a activity that the subjective awareness of educators. This kind of subjective consciousness contains the educators' value choice and value preset. The value guidance of Sex education should start from physical and mental development of young people. Sexual attitudes of young people to guide both the value of respect for traditional values, while respecting students' personal experience. To guide the focus of the concept of value is to guide young people distinguish between good and evil and eventually form the liberal sexual values. We should guide young people to establish self-education and self-enjoyed liberal sexual values. At the same time, we should respect young people's individuality and independent personality.

\section{People-Oriented Sexual Education}

The slogan of people-oriented in education is not a new word. Sex education is not just knowledge, but also sexual morality, sexual values of education. The implementation of sex education for students should include all aspects from the outset. Students are the recipients in sex education, but are not passive to accept the knowledge of sex. This is far to achieve their educational goals. Educators should also totally understand the students and do not take the student as the ignorant people. Trying to know what the original knowledge which is correct they have got.

\section{Diversify Students' Moral Character}

Many schools in the United States launched a sex education class discussion and allowed students to express their views on particular issues in the class. Through organizing the student to carry on some social activities to cultivate the social morality and urge them to be a social ethics person as a goal. Teachers should be in frank of sex education and communication with students naturally. The purpose of education is through education that young people can correctly understand the nature and have the necessary knowledge.

On one hand sex education is more and more progressive to teach sexual knowledge in our country, but on the other hand sexual moral issue is a serious problem. Parents don't talk about this topic with their children, and the school did not teach students such kind of knowledge. The psychological needs and behavior of young people choose a serious absence of appropriate guidance.

\section{Common Maintenance of School, Family and Society}

As with other educational contents, campus sex education also needs support. Most Chinese parents have traditional idea that is the less you know the better. Meanwhile, they are ashamed to 
teach their children sexual knowledge. They dare to make up their mind on other aspects of education for children except the sexual knowledge. If parents and children on sexual issues openly, then the child's attitude towards sex and sexual values will be more active and healthy.

\section{Conclusion}

China has accumulated a lot of experience for moral education to students in many years. There are many good ideas and methods, which can be applied to sex education. So, reflecting on the implementation of sex education in our country, there are few teachers engaged in sex education of using the method of moral lessons to guide students. Promote sexual morality and proper sexual values and sex education should become a long-term social utility.

It seems that American parents do much better than Chinese parents. The community should give sex education much more support. The social health organization is conducive to promoting the development of the adolescent sexual health. At the same time, a variety of community groups can offer special services for sex education in schools.

\section{Acknowledgement}

My sincere gratitude goes to all those teachers of the Foreign Language Department, whose instructive lectures are of great help for the completion of this dissertation. But here I must offer specific thanks to my supervisor, Mr Liu Zijian, who gave me very helpful guidance and provided extremely useful comments on the whole draft.

I would also express the sincere appreciation to my good friend Lisa, who helped me find materials related to my dissertation.

In addition, I would owe great gratitude to my classmates Guilan Zhong, Yanli Sun, Xiumei Li, who helped me in the process of accomplishment of my dissertation.

\section{References}

[1] Zhan Wendu, Strengthen Moral Education Adolescent Sex--from the Contemporary Western (BeiJing: The contemporary youth research, 2001)45.

[2] Chu Lixia,Theory of Internet Porn and Adolescent Sex Moral Education.(Theory and modern Change, 2006)102.

[3] Yan Weiguang,Puberty Parents of Sexual knowledge of Sex Education and Their Attitude of Tone Check(China My School Doctor,2005).36

[4] Fan Minwins,Pay Attention to Adolescent Sex Education Morality.(Chinese Sexual Science,2004)19.

[5] Xuli,Liushuang,For Teenage Sex knowledge,Attitude and Behavior Patterns and Sex Education Status.(Chinese Science,2000)51.

[6] Xi Jieying,The New State of Contemporary Urban Youth Report(1997-1998)168

[7] Vasyl Sukhomlynsky,How to Raise the Real People.(Beijing:Teach Yukon Science Press, 1999)271

[8] National Public Radio et al. Sex Education in America: NPR /Kaiser/Kennedy School Poll. Menlo Park (CA: Kaiser Family Foundation, 2004).

[9] Alford, S. et al. Science and Success: Sex Education and Other Programs That Work to Preventteen pregnancy, H IV and Sexually Transmitted Infections. (Washington, D. C: Advo2 Cates for Youth, 2003)

[10] Su Ying. Relationship between Mental Health Status and Personality Traits of Children in a 
Beijing Orphanage (Health Science Center of Peking University, Beijing 100191,P.R.China, China Journal of Health Psychology, 2011). 